\title{
Factors associated with consultation behaviour for primary symptoms potentially indicating colorectal cancer: A cross-sectional study on response to symptoms
}

\author{
Ryan J Courtney ${ }^{1,2^{*}+}$, Christine L Paul ${ }^{1,2 \dagger}$, Robert W Sanson-Fisher ${ }^{1,2+}$, Finlay A Macrae ${ }^{3 \dagger}$, John Attia ${ }^{2,4 \dagger}$
} and Mark McEvoy ${ }^{2,4 \dagger}$

\begin{abstract}
Background: Little data exists on the factors associated with health care seeking behaviour for primary symptoms of colorectal cancer (CRC). This study aimed to identify individual, provider and psychosocial factors associated with (i) ever seeking medical advice and (ii) seeking early medical advice for primary symptoms of colorectal cancer (CRC).

Methods: 1592 persons aged 56-88 years randomly selected from the Hunter Community Study (HCS) were sent a questionnaire.

Results: Males and those who had received screening advice from a doctor were at significantly higher odds of ever seeking medical advice for rectal bleeding. Persons who had private health coverage, consulted a doctor because the 'symptom was serious', or who did not wait to consult a doctor for another reason were at significantly higher odds of seeking early medical advice $(<2$ weeks). For change in bowel habit, persons with lower income, within the healthy weight range, or who had discussed their family history of CRC irrespective of whether informed of 'increased risk' were at significantly higher odds of ever seeking medical advice. Persons frequenting their GP less often and seeing their doctor because the symptom persisted were at significantly higher odds of seeking early medical advice $(<2$ weeks).

Conclusions: The seriousness of symptoms, importance of early detection, and prompt consultation must be articulated in health messages to at-risk persons. This study identified modifiable factors, both individual and provider-related to consultation behaviour. Effective health promotion efforts must heed these factors and target sub-groups less likely to seek early medical advice.
\end{abstract}

\section{Background}

Colorectal cancer (CRC): the burden of illness

Internationally, CRC is diagnosed in over one million persons annually (9.4\% of all cancer diagnoses) and ranks as the fourth leading cause of cancer related death [1]. On average, $50 \%$ of CRC cases are living five years

* Correspondence: ryan.courtney@newcastle.edu.au

${ }^{\dagger}$ Equal contributors

${ }^{1}$ The Priority Research Centre for Health Behaviour, School of Medicine and

Public Health, Faculty of Health, The University of Newcastle, Newcastle,

Australia

${ }^{2}$ Hunter Medical Research Institute, Newcastle, NSW, Australia

Full list of author information is available at the end of the article following diagnosis [2-4]. Survival rates for CRC are inversely related to stage at diagnosis with early stagedlocalised CRC 5-year survival rate at 90\% compared to approximately $10 \%$ for distant metastatic CRC [5]. The rate of early detection is relatively low with approximately $40 \%$ of CRC patients diagnosed at a localised stage [5].

Primary symptoms and clinical presentation of CRC Rectal bleeding and change in bowel habit are common potential symptoms of CRC experienced in the population [6-9]. Past studies have estimated $37-84 \%$ of all 
CRCs present with rectal bleeding [10-12]. Change in bowel habit, broadly termed as diarrhoea or constipation, generally refers to a change in frequency of defecation, consistency of stool, shape of stool or difficulty in evacuation [13]. Change in bowel habit is the symptom most associated with patient delay in presentation [14] and presents in approximately $48-77 \%$ of CRCs, with increased frequency of defecation/diarrhoea accounting for the largest proportion of cases [10-12].

\section{The paradoxical relationships among symptom duration, colorectal cancer staging and survival}

The paradoxical relationship between symptom duration, CRC staging and survival continues to be debated in the literature [10,15-17]. Intuitively, a reduction in diagnostic and therapeutic delay should be accompanied by an improved survival rate [17]. This has been supported for breast cancer, with delays of 3-6 months associated with poorer survival [18], however, for CRC, it is axiomatic that reduced diagnostic and treatment delay will be accompanied by earlier-stage detection and improved prognosis [19]. Several studies have indicated that symptom duration is unrelated to pathological stage at diagnosis [10,20,21]. A potential explanation for this paradoxical finding may be the limited potential benefit of early detection and treatment for those persons with particularly aggressive tumour biology [22]. Conversely, other studies have indicated that patients with symptom duration equal to or greater than 3 months are less likely to have Stage 1 tumours [23,24]. Although inconclusive, other studies have indicated an inverse relationship, whereby a shorter symptom duration period is associated with poorer staging and survival $[25,26]$.

It is important however that the necessity of prompt medical advice seeking is not forgotten especially given that only a minority of CRC cases are detected asymptomatically through screening, between $5-20 \%$ of all cases $[14,27]$. While the pattern of presentation is slowly changing towards more CRCs being identified through screening, for the foreseeable future, the high rate of symptomatic presentation to the health care system is likely to continue $[28,29]$. Most commonly the first step towards diagnosis is via symptomatic presentation to primary care $[14,28]$ with approximately a quarter of symptomatic cases presenting as an emergency [28-31], usually with bowel obstruction [32]. Studies examining emergency presentation to hospital departments have indicated a median symptom duration of three months prior to admission, without patients necessarily presenting at any earlier point to primary care [33,34]. For cases presenting to emergency, the mortality rate [35] and five year-survival rate is poor [36-38], likely because of the serious state of illness across multiple organ systems that patients develop after obstruction occurs. A recent UK
National Health Service review of the "Two Weeks" program indicated that reduction in delay can have the important patient outcome of minimising complications, e. g. bowel obstruction, which may have an effect on survival [39]. Ideally, a large public health gain may be achieved for the late-presenting patient group if medical intervention occurs at an earlier stage and the proportion of emergency admitted cases is decreased [40].

\section{Bridging the evidence practice gap}

Our understanding of the factors associated with medical advice seeking behaviour for primary symptoms potentially indicating CRC is largely restricted to a few community and population-based studies, predominantly focusing on rectal bleeding. An Australian community-based study indicated that divorced, separated or retired persons were more likely to ever consult a doctor for rectal bleeding [6]. Other international studies have identified that the following predict ever seeking care for CRC symptoms in the community setting: older age (> 45 years), being a non-smoker, being employed, having constipation rather than diarrhoea, and symptom specific characteristics such as greater concern, severity, and frequency of symptoms [41,42]. In relation to early medical advice seeking, the literature has largely focused on those delaying greater than three months $[6,43]$. Previous research suggests that adults experiencing rectal bleeding delay or fail to consult a doctor due to a perception that the condition is not serious $[6,7,43]$. Identified triggers for seeking medical advice for rectal bleeding include: greater perceived seriousness, persistence and/or nuisance of the symptom, pain or discomfort, opportunity during an existing consultation to discuss the symptom, and pressure from a relative [44,45]. Previous literature relating to CRC patients health care seeking behaviour have also highlighted other key factors associated with patient delay including: patient appraisal, recognition and knowledge of symptoms, symptom characteristics, and emotional response to symptoms [46-50].

Little is known about medical advice seeking for change in bowel habit, which is limited to a handful of studies more generally examining medical consultation rather than time taken to seek medical advice $[41,51,52]$. The current study seeks to identify the factors associated with medical advice seeking behaviour for primary symptoms of CRC. Identification of population or individual characteristics associated with earlier medical consultation is important in shaping future public-health messages aimed at encouraging prompt medical advice seeking in the at-risk community. Therefore, this study retrospectively examined socio-demographic, provider and psychosocial factors associated with the following 
practices among an at-risk (56-88 years of age) cohort of community dwelling persons:

1. Ever seeking medical advice for rectal bleeding and change in bowel habit.

2. Early medical advice seeking for rectal bleeding ( $<2$ weeks) and change in bowel habit ( $<4$ weeks).

\section{Methods}

\section{Design and study population}

The Hunter Community Study (HCS) is a longitudinal cohort of community dwelling men and women aged 55-85 years at baseline from the Hunter Region, NSW, Australia [53]. Participants were randomly selected from the NSW State electoral roll between December 2004 and 2007. The HCS cohort provides a population profile reflecting that of the Hunter Region, state and national Australian profiles for gender and marital status but is slightly younger in age [53]. A randomly selected subsample of HCS participants $(\mathrm{n}=1592)$ aged between 56 and 88 years at time of survey (November, 2009) were mailed a pen and paper questionnaire. A reminder telephone call was made to non-responders at 4-6 weeks following initial mail out.

\section{Questionnaire}

Respondents were asked separately whether they had ever experienced either rectal bleeding or a persistent change in bowel habit (diarrhoea/constipation) that lasted longer than two weeks. These items were used to determine the proportion of respondents ever experiencing each symptom. The item concerning rectal bleeding had been used in two previous Australian studies $[6,43]$ while the change in bowel habit item was devised for this study. Details regarding rates of medical advice seeking are provided elsewhere [54]. Respondents indicating they had ever experienced either symptom were asked whether they had ever seen a doctor about that particular symptom. Response to this question, for both symptoms was used to identify the proportion who had ever sought medical advice from a doctor. Respondents indicating they had ever consulted a doctor were asked if they had noticed this symptom for the first time in the previous five years. To reduce recall bias only respondents experiencing their first symptom episode in the last five years and consulting a doctor were included in the analyses of early medical advice seeking. Such respondents were asked to specify the time taken to seek medical advice and trigger(s) for seeking medical advice. The response options relating to triggers for seeking medical advice were forced choice with an "Other (Please specify)" option included. For rectal bleeding, location of bleeding, colour, frequency and level of concern were assessed. For change in bowel habit, type of irregular bowel movement, level of discomfort/pain, and frequency of symptom were assessed.

All respondents were asked about their family history of CRC and age at diagnosis across first and second degree relatives. Respondents answers to questions relating to doctor screening of family history of CRC and identification of any possible 'increased risk' were used to derive a family history of CRC discussed with doctor variable with three levels (never discussed, discussed and informed of possible 'increased risk', discussed and not informed of possible 'increased risk'). Respondents were also asked to indicate whether a doctor or other health professional had ever provided CRC screening advice. 'An additional questionnaire file shows in more detail questions and response options used in this study [see Additional file 1].

\section{Predictors}

Based on existing literature relating to the barriers and facilitators of medical advice seeking, an a priori investigation of the following items selected from the HCS databank were assessed: Socio-demographic and lifestyle characteristics, i.e. age, gender, education, marital status, country of birth, household income, retirement, private health insurance status, tobacco or alcohol use; Clinical characteristics i.e. general practice visits per year, previous cancer diagnosis (excluding CRC), body mass index, and co-morbidity (e.g. high cholesterol, hypertension, asthma, diabetes); and Psychosocial characteristics i.e. physical health, assessed using the physical health component summary score (PCS) on the short form health survey (SF-36) [55] and mental health, assessed using the Kessler Psychological Distress Scale (K-10) [56]. The PCS is a physical health summary score aggregated from the physical functioning, role-physical, bodily pain and general-health scales on the SF-36 [57]. Predictors ascertained from respondents at the time of survey completion included: trigger for seeking medical advice, symptom characteristics, first degree relative diagnosed with CRC, family history of CRC discussed with doctor, and ever received screening advice from doctor.

\section{Statistical analyses}

Logistic regression analysis was used to determine independent factors associated with ever seeking medical advice (never consulted, consulted) and early medical advice seeking ( $<2$ weeks for rectal bleeding and $<4$ weeks for change in bowel habit). Variables with a $p<.25$ following simple regression analysis (see Appendix) were considered for multiple logistic regression modelling (both forward and backward stepwise elimination were used to check consistency of results). Variables that met the significance cut point of $p<.05$ were retained in 
the final model. Data were analysed using STATA 11 (STATA, Texas, USA).

\section{Ethics approval}

The University of Newcastle in partnership with the Hunter New England Population Health Human Research Ethics Committee granted ethical approval (H-820-0504).

\section{Results}

Sample demographics

Of the 1592 mailed surveys, 1117 respondents completed and returned a survey (consent rate $=70 \%$ ). Respondents previously diagnosed with colorectal carcinoma $(n=24)$ or reporting they had undergone major abdominal surgery $(n=8)$ were excluded from analysis, leaving a total sample of 1085 eligible participants for analysis. For participants diagnosed with CRC or having undergone abdominal surgery information relating to the date of CRC diagnosis/abdominal surgery was not obtained. The timing of such an event (before or after) symptom episode is critical to understanding health care seeking behaviour for such respondents. To eliminate the potential for bias in study results persons diagnosed with CRC or having undergone abdominal surgery were excluded. Demographic characteristics of the sample are presented in Table 1.

\section{Rectal bleeding}

Of the 1075 respondents to the rectal bleeding question, 332 (31\%) reported ever experiencing this symptom with $60(18 \%)$ respondents never having consulted a doctor. Additional file 2 presents the univariate (Pearson $\chi^{2}$ ) associations between socio-demographic, clinical and psychosocial characteristics and ever seeking medical advice for rectal bleeding. Multiple logistic regression modelling identified the following significant predictors of ever seeking medical advice for rectal bleeding: being male and persons that had ever received screening advice from a doctor or other health professional (See Table 2).

Of the 332 respondents ever experiencing rectal bleeding, 30\% (101/332) had experienced their first symptom episode in the previous five years and consulted a doctor. These respondents were included in the analyses for early medical advice seeking, in which $67 \%$ of persons had consulted a doctor within two weeks. Multiple logistic regression modelling (see Table 3 ) identified that early medical advice seeking ( $<2$ weeks) was significantly associated with private health coverage and participant trigger for seeking medical advice - 'Thought the symptom was serious'. Persons indicating the prompting factor for consultation was "Opportunity to talk during doctor visit for other reason" were less likely to seek early medical advice.
Table 1 Demographic characteristics of study respondents $(n=1085)$

\begin{tabular}{lll}
\hline & $\boldsymbol{n}$ & $\%$ \\
\hline Gender & 508 & 47 \\
\hline Male & 577 & 53 \\
\hline Female & & \\
\hline Age (years) & 455 & 42 \\
\hline $56-64$ & 382 & 36 \\
\hline $65-74$ & 237 & 22 \\
\hline $75-88$ & & \\
\hline Country of Birth & 885 & 89 \\
\hline Australia & 111 & 11 \\
\hline Other & & \\
\hline Marital status & 805 & 77 \\
\hline In a relationship & 240 & 23 \\
\hline Not in relationship & & \\
\hline Annual household income before tax (\$) & 574 & 58 \\
\hline$<=39,999$ & 216 & 22 \\
\hline 40,000 - 69, 999 & 197 & 20 \\
\hline$>=70,000$ & 253 & 22 \\
\hline Highest Level of Education & 229 & 22 \\
\hline Secondary schooling (not-completed) & 264 & 25 \\
\hline Secondary schooling (completed) & & \\
\hline Trade qualification or TAFE: & & 25 \\
\hline University or other tertiary study & & \\
\hline Other or not applicable & & \\
\hline Percentage of responses (excluding any missing values) & & \\
\hline
\end{tabular}

* Percentage of responses (excluding any missing values).

\section{Change in bowel habit}

For change in bowel habit, 1049 respondents answered this question; 195 (19\%) reported ever experiencing this symptom, of which 39 (20\%) respondents never consulted a doctor. Following multiple logistic regression modelling ever seeking medical advice for change in bowel habit was significantly more likely for persons: who had discussed their family history of CRC, irrespective of whether they were informed of possible 'increased

\section{Table 2 Multiple logistic regression analysis of factors associated with ever seeking medical advice for rectal bleeding}

\begin{tabular}{lll}
\hline & OR $\mathbf{( 9 5 \% ~ C l )}$ & $\boldsymbol{p}$ value \\
\hline Gender & 1 & \\
\hline Male & $.51(.26, .98)$ & .045 \\
\hline Female & & \\
\hline Screening advice from doctor & $4.45(1.90,10.41)$ & .001 \\
\hline Yes & 1 & \\
\hline No &
\end{tabular}


risk' or not, with a lower household income, and who were within the healthy BMI weight range (See Table 4).

Of the 195 respondents ever experiencing a change in bowel habit persisting longer than two weeks, 37\% (72/ 195) of persons had experienced this symptom for the first time in the previous five years and consulted a doctor. For this group, 63\% of respondents respectively sought medical advice within four weeks. Multiple regression modelling indicated that early medical advice seeking ( $<4$ weeks) was significantly associated with persons who had: identified as a prompting factor for medical consultation - "Symptom didn't go away"; fewer GP visits per year; and discussed their family history of CRC with a doctor and were notified of a possible 'increased risk' (See Table 5).

\section{Discussion}

To our knowledge this study is the first to assess factors associated with early medical advice seeking behaviour for primary symptoms potentially indicating CRC. Previous studies have generally focused on rectal bleeding and the reasons for non-consultation or delay greater than three months $[6,7,43]$. For change in bowel habit, the current investigation of early medical advice seeking is timely given that research to date has generally examined factors associated with the decision to consult, rather than early medical advice seeking behaviour.

\section{Failure to seek medical advice}

The present study has highlighted that for both primary symptoms approximately one in five persons who had experienced symptoms had never consulted a doctor at any stage in their lifetime. A recent Australian population-based study of persons aged over 18 years indicated that $69 \%$ of respondents experiencing rectal bleeding had not presented to their physician in the previous year [58]. Other community-based studies have indicated that for persons aged over 40 years, approximately one-third either fail to seek, or delay (> 3 months) seeking medical advice for rectal bleeding [6,43]. A community

Table 3 Multiple logistic regression analysis of factors associated with early medical advice seeking for rectal bleeding

\begin{tabular}{lll}
\hline & OR $(\mathbf{9 5 \%} \mathrm{Cl})$ & $\boldsymbol{p}$ value \\
\hline Private health insurance & & \\
\hline No coverage & 1 & \\
\hline Coverage & $3.96(1.11,14.19)$ & .034 \\
\hline Prompt for medical consultation. & & \\
\hline Thought the symptom was serious' & $5.88(1.48,23.30)$ & .012 \\
\hline $\begin{array}{l}\text { 'Opportunity to talk during doctor } \\
\text { visit for other reason }\end{array}$ & $.15(.04, .52)$ & .003 \\
\hline $\begin{array}{l}\text { OR, odds ratio; Cl, confidence interval. } \\
\end{array}$
\end{tabular}

$\mathrm{OR}$, odds ratio; $\mathrm{Cl}$, confidence interval.
Table 4 Multiple logistic regression analysis of factors associated with ever seeking medical advice for change in bowel habit

\begin{tabular}{|c|c|c|}
\hline & OR $(95 \% \mathrm{Cl})$ & $p$ value \\
\hline \multicolumn{3}{|l|}{ Annual household income before tax (\$) } \\
\hline$<=39,999$ & 1 & \\
\hline$\$ 40,000-\$ 69,999$ & $.36(.13, .95)$ & .038 \\
\hline$>=\$ 70,000$ & $.29(.10, .86)$ & .027 \\
\hline \multicolumn{3}{|l|}{ BMl } \\
\hline$<18.5$ & - & \\
\hline $18.5-25$ & 1 & \\
\hline$>25$ & $.12(.03, .59)$ & .009 \\
\hline \multicolumn{3}{|l|}{ Family history of CRC discussed with doctor } \\
\hline Never discussed & 1 & \\
\hline Discussed/informed of 'increased risk' & $5.68(1.72,18.75)$ & .004 \\
\hline Discussed/not informed of increased 'risk' & $2.90(1.06,7.94)$ & .038 \\
\hline
\end{tabular}

based-study conducted in the United States identified that $86 \%$ of respondents experiencing rectal bleeding had failed to seek medical care within the prior year [59]. UK based studies have also indicated a high rate of non-consultation, between $59 \%-82 \%$ of respondents experiencing rectal bleeding $[44,60]$. For change in bowel habit, the literature is less developed. A UK study indicated that $76 \%$ of persons experiencing lower gastrointestinal symptoms (including functional bowel disorders) had failed to ever consult a doctor [41].

\section{Public health gain: decreasing CRC patients admitted to acute settings}

At present, an alarming rate of $20-40 \%$ of all CRC cases present as a medical emergency [28,35,61]. Previous studies have indicated that symptomatic persons presenting to emergency departments report a median symptom duration of 3 months prior to admission, without necessarily presenting at an earlier point of intervention to primary care [33,62]. For cases presenting to emergency departments, the mortality rate is higher [35]

Table 5 Multiple logistic regression analysis of factors associated with early medical advice seeking for change in bowel habit

\begin{tabular}{lll}
\hline & OR $(\mathbf{9 5} \% \mathbf{C l})$ & $\boldsymbol{p}$ value \\
\hline Every increase in GP visits per year & $.52(.31, .88)$ & .014 \\
\hline Prompt for medical consultation & & \\
\hline 'Symptom didn't go away' & $5.75(1.42,23.24)$ & .014 \\
\hline Family history of CRC discussed with doctor & & \\
\hline Never discussed & 1 & \\
\hline Discussed/informed of 'increased risk' & $6.37(1.04,38.92)$ & .045 \\
\hline Discussed/not informed of increased 'risk' & $3.73(.82,16.97)$ & .089 \\
\hline OR, odds ratio; Cl, confidence interval. & &
\end{tabular}


and the cancer specific five year-survival rate is lower [36-38] which indicates that a significant public health gain is achievable if cases are identified and appropriately investigated within the primary health care setting [63]. Further, it is conceivable that improvements in earlier recognition of symptoms and immediate presentation to primary care could reduce the number of CRC cases requiring acute management options e.g. surgery for bowel obstruction. In theory, some emergency presentations should be prevented yet are not [33]. There is considerable room for improvement, with a significant proportion of community members (approximately $20 \%$ across both symptoms) never seeking medical advice for either potential symptom of CRC.

\section{Factors associated with ever seeking medical advice}

Male persons were significantly more likely to seek medical advice for rectal bleeding. This finding is inconsistent with previous literature that has indicated males are less likely to present for medical care across a wide-trajectory of health issues $[64,65]$. Nonetheless, previous communitybased studies relating to medical consultation for bowel related symptoms have generally indicated no gender difference $[6,66]$. Further, a systematic review of delay in diagnosis of CRC highlighted that sex had no impact on presentation times [67]. Future exploration of the barriers to help seeking for rectal bleeding among female persons and addressing such behaviours in public awareness campaigns may assist in improving overall consultation rates.

The present study identified that persons experiencing rectal bleeding who had ever received screening advice from a doctor or other health professional were significantly more likely to have ever sought medical advice. For this finding, the exact temporal sequencing of events was not ascertained, making extrapolation of exact cause and effect difficult. Intuitively persons may have experienced rectal bleeding, consulted a doctor and received screening advice after symptom episode. Alternatively persons may have received screening advice prior to symptom episode, with recollection of such a conversation prompting the increased likelihood of medical consultation. This temporal sequencing issue also relates to our finding that discussion of family history, regardless of whether the respondent was informed of increased risk, resulted in increased likelihood of ever consulting a doctor for change in bowel habit. Future research is required that clarifies the sequence and timing of such events.

Persons experiencing change in bowel habit with a lower household income were found to be significantly more likely to ever seek medical advice compared to persons with higher household income. In contrast, other communitybased studies have found no relationship between socioeconomic status and help seeking behaviour for rectal bleeding [42]. Similarly, no relationship between socio- economic status and help-seeking behaviour has been identified in relation to other cancer related symptoms [42,68]. Given the scant literature examining change in bowel habit and earlier presentation time, further investigation of broader socio-economic constructs effect on helpseeking behaviour is required.

\section{Factors associated with early medical advice seeking}

The current study indicated that persons with private health coverage were significantly more likely to seek early medical advice for rectal bleeding. Such a finding is not surprising, given that persons without health insurance are known to have limited access to medical care [69] and poorer health outcomes [70,71] compared to privately insured persons. For this group it is proposed that increased morbidity and mortality of CRC is a result of restricted access to medical and surgical care [70,72]. In relation to CRC, health insurance status heavily influences access to care, screening and long-term outcomes $[70,72,73]$. Previous research has indicated that persons without health insurance are more likely to present with advanced cancer [73]. For CRC, uninsured and Medicaid populations have been found to be at greater risk of developing post-operative complications and in-hospital mortality compared to those privately insured [72]. More recent research also highlights longer pre- and postpresentation times for CRC patients without private health insurance [27]. Restricted access to health care or more concerning, lack of any medical advice seeking for those without private health insurance raises significant issues relating to possible delayed diagnosis, worse overall health, and advanced disease progression.

\section{Triggers of early medical advice seeking}

Previous community and population-based studies have identified that perceived symptom seriousness is an important factor in eliciting medical consultation for rectal bleeding $[44,45]$. Studies that have examined retrospective recall of cancer patients have commonly identified that failure to recognise symptom seriousness is a significant factor associated with patient delay [74]. Previous population-based studies have indicated that failure to consult or delay (> 3 months) in seeking medical advice for rectal bleeding is due to an underestimation of symptom seriousness $[6,43]$. A similar finding has been demonstrated for patients recruited in the general practitioner setting [44]. The current study indicated that persons perceiving their symptom as serious were more likely to see a doctor at an earlier time point $(<2$ weeks). This finding suggests that perception of symptom seriousness is not just an important factor for medical consultation but also contributes to earlier presentation time. Intuitively future health messages directed at the at-risk community must articulate the serious nature of primary symptoms of CRC 
and the importance of early medical advice seeking for improved health outcomes.

The current research also indicated that persons indicating that their trigger for medical consultation was "Opportunity to talk during visit for other reason" were more likely to not seek earlier medical advice. Such a finding suggests a person's willingness to 'sit on symptoms' until another health issue or alternate reason for medical consultation arises. Encouragingly, current health messages worldwide are targeting this sub-group of persons with the "Don't sit on your symptoms" campaign $[75,76]$. In relation to change in bowel habit, persons identifying "Symptom didn't go away" as a trigger for medical consultation were more likely to consult at an earlier time point (< four weeks) compared to persons not identifying with this trigger.

\section{The need for improved medical advice seeking behaviour in the primary care setting}

The study results suggest that there may be room for improvement in the identification of symptomatic patients in the primary care setting. General Practitioners (GPs) are in an ideal position to systematically offer information to patients with $88 \%$ of persons presenting to a GP annually, 30\% aged 65 years or older [77]. Routine health screening relating to bowel related health may encourage earlier identification of symptoms. The acceptability and feasibility of systematic assessment of ovarian symptoms during GP practice visits is currently being assessed in the general practice setting [78]. A similar mechanism could be incorporated to monitor for potential symptom indicators of CRC, with particular attention on those subgroups who are less likely to seek prompt medical advice for symptoms.

\section{Study limitations}

This study includes some limitations that should be considered when interpreting study results. The main limitation is a reliance on self-reported recall with no objective verification of symptom episode and time taken to seek medical advice. It is possible that recall bias may have affected some reports given that respondents were asked to report on circumstances that had occurred up to five years previously. To enhance respondents' recall of the time taken to seek medical advice for primary symptoms of CRC, analysis was restricted to persons who had experienced their first symptom episodes in the previous five years and had consulted a doctor during this timeframe. This technique was adopted, as in other previous studies [6 43], to reduce the influence of potential recall bias. Nonetheless, this inherent limitation of studies using retrospective self report may be improved in the future through the adoption of a shorter recall period from symptom onset. Further, it should be considered that a conservative cut-point was used to denote early medical advice seeking for rectal bleeding ( $<2$ weeks) and change in bowel habit $(<4$ weeks). Clinical practice guidelines in Australia and the United Kingdom (UK) do not specify a timeframe for at-risk persons (aged 50 years or over) to seek medical advice for primary symptoms of CRC $[79,80]$. In relation to rectal bleeding, at-risk persons are encouraged to seek prompt medical advice following symptom episode $[79,80]$. In relation to change in bowel habit, Australian guidelines encourage at-risk persons to seek medical advice but do not specify an exact time period [79]. However, guidelines in the UK do specify that persons 60 years or over experiencing changed bowel habit for longer than 6 weeks with no other anal symptoms be urgently referred [80]. Research on the predictive value of symptoms and patient delays effect on staging and prognosis of CRC should be used to inform any future amendments to guidelines or public health messages relating to "prompt" medical advice seeking behaviour. Finally, it must be noted that the relationship between the timing of discussions about family history of CRC with a doctor and provision of screening advice with symptom onset was not clearly delineated in the survey. Nonetheless, it is reasonable to assume that where health care providers have previously raised the issue of CRC, patients may subsequently feel more open about discussing potential symptoms and realise the importance of discussing symptoms.

\section{Conclusions}

The high rate of failure to ever seek medical advice for primary symptoms potentially indicating CRC is an issue requiring public health action. Education about the seriousness of symptoms, particularly rectal bleeding and change in bowel habit in people over 50 years, and the need for early medical advice is required. Study results suggest the need for targeting of specific sub-groups in future public health messages encouraging prompt medical advice seeking. Importantly, patient delay in seeking medical advice is a modifiable factor that must be addressed if the burden of illness associated with CRC is to be reduced. Interventions within the primary health care setting are an important starting point to reach this critical endpoint.

\section{Additional files}

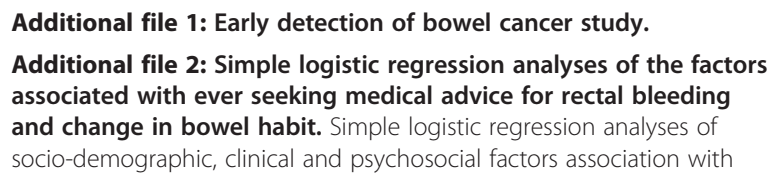

Competing interests

The authors declare that they have no competing interests. 


\section{Authors' contribution}

Authors (RC, CP, RSF) made substantial contributions to the conception and design of the study. Data analysis was conducted by RC. All authors' (RC, CP, RSF, FM, JA, MM) made substantial contributions to interpretation of data, drafting and editing of the manuscript and have given their approval of the manuscript for publication. All authors read and approved the final manuscript.

\section{Acknowledgements}

The research on which this paper (book, monograph, abstract, or report) is based was conducted as part of the Hunter Community Study, The University of Newcastle. We are grateful to The University of Newcastle, the Hunter Medical Research Institute \& Lion's Club of Adamstown for funding and to the men and women of the Hunter region who provided the information recorded. We thank Roseanne Peel for her contribution to the development of the studied cohort; Stephen Hancock for design of the current study's database; Tracey Watt for her assistance with data entry and the mail out/reminder call process; and Daniel Barker and Michael Fitzgerald for their statistical support. Recognition and thanks to Australian Rotary Health Research Fund and the Rotary District 9650 Bowelscan Committee for their funding of PhD scholar - RJC.

\section{Author details}

${ }^{1}$ The Priority Research Centre for Health Behaviour, School of Medicine and Public Health, Faculty of Health, The University of Newcastle, Newcastle, Australia. ${ }^{2}$ Hunter Medical Research Institute, Newcastle, NSW, Australia. ${ }^{3}$ Department of Colorectal Medicine and Genetics, The Royal Melbourne Hospital, Melbourne, Australia. ${ }^{4}$ The Centre for Clinical Epidemiology and Biostatistics, Faculty of Health, The University of Newcastle, Newcastle, Australia.

Received: 6 December 2011 Accepted: 26 July 2012

Published: 3 August 2012

\section{References}

1. Boyle P, Levin B: World Cancer Report. World Health Organisation. International Agency for Research on Cancer. http://www.iarcfr/en/publications/pdfs-online/wcr/.

2. Pisani P, Parkin DM, Ferlay J: Estimates of the worldwide mortality from eighteen major cancers in 1985. Implications for prevention and projections of future burden. Int J Cancer 1993, 55:891-903.

3. Pisani P, Parkin DM, Bray F, Ferlay J: Estimates of the worldwide mortality from 25 cancer in 1990. Int J Cancer 1999, 83:18-29.

4. Wingo PA, Cardinez CJ, Landis SH, Greenlee RT, Ries LA, Anderson RN, Thun MJ: Long-term trends in cancer mortality in the United States, 1930-1998. Cancer 2003, 97:3133-3275.

5. Howlader N, Noone AM, Krapcho M, Neyman N, Aminou R, Waldron W, Altekruse SF, Kosary CL, Ruhl J, Tatalovich Z, Cho H, Mariotto A, Eisner MP, Lewis DR, Chen HS, Feuer E, Cronin KA, Edwards BK: Surveillance Epidemiology and End Results Cancer Statistics review; 1975-2008. http://seer.cancer.gov/csr/1975_2008/index.html.

6. Cockburn J, Paul C, Tzelepis F, McElduff P, Byles J: Delay in seeking advice for symptoms that potentially indicate bowel cancer. Am J Health Behav 2003, 27:401-407.

7. Crosland A, Jones R: Rectal bleeding: prevalence and consultation behaviour. BMJ 1995, 311:486-488

8. Ellis BG: Factors identifying higher risk rectal bleeding in general practice. Br J Gen Pract 2005, 55:949-955.

9. Talley NJ, Jones M: Self-reported rectal bleeding in a United States community: prevalence, risk factors, and health care seeking. Am J Gastroenterol 1998, 93:2179-2183.

10. Kiran PR, Glass RE: Duration of symptoms and spread of colorectal cancer: a short history does not mean early disease. Ann R Coll Surg Engl 2002, 84:381-385.

11. Majumdar S, Fletcher R, Evans A: How does colorectal cancer present? Symptoms, duration, and clues to location. Am J Gastroenterol 1999, 94:3039-3045.

12. Smith D, Ballal M, Hodder R, Soin G, Selvachandran S, Cade D: Symptomatic presentation of early colorectal cancer. Ann R Coll Surg Engl 2006, 88:185-190.

13. John SKP, George S, Primrose JN, Fozard JBJ: Symptoms and signs in patients with colorectal cancer. Colorectal Dis 2010, 13:17-25.

14. Hamilton W, Sharp D: Diagnosis of colorectal cancer in primary care: the evidence base for guidelines. Fam Pract 2004, 21:99-106.

15. Korsgaard M, Pedersen L, Sorensen HT, Laurberg S: Reported symptoms, diagnostic delay and stage of colorectal cancer: a population-based study in Denmark. Color Dis 2006, 8:688-695.
16. Ramos M, Esteva M, Cabeze E, Llobera J, Ruiz A: Lack of association between diagnostic and therapeutic delay and stage of colorectal cancer. Eur J Cancer 2008, 44:510-521.

17. Ramos M, Esteva M, Cabeza E, Campillo C, Llobera J, Aguilo A, Ramos M, Esteva M, Cabeza E, Campillo C, Llobera J, Aguilo A: Relationship of diagnostic and therapeutic delay with survival in colorectal cancer: a review. Eur J Cancer 2007, 43:2467-2478.

18. Richards MA, Westcombe AM, Love SB, Littlejohns P, Ramirez AJ: Influence of delay on survival in patients with breast cancer: a systematic review. Lancet 1999, 353:1119-1126.

19. Macrae F: Providing colonoscopy services for the National Bowel Cancer Screening Program. Med J Aust 2007, 186:280-281.

20. Gonzalez-Hermoso F, Perez-Palma J, Marchena-Gomez J, Lorenzo-Rocha N, Medina-Arana V: Can early diagnosis of symptomatic colorectal cancer improve the prognosis? World J Surg 2004, 28:716-720.

21. Kyle SM, Isbister WH, Yeong ML: Presentation, duration of symptoms and staging of colorectal carcinoma. ANZ J Surg 1991, 61:137-140.

22. Stapley S, Peters TJ, Sharp D, Hamilton W: The mortality of colorectal cancer in relation to the initial symptom at presentation to primary care and to the duration of symptoms: a cohort study using medical records. Br J Cancer 2006, 95:1321-1325.

23. Olsson L, Bergkvist $L$, Ekbom A: Symptom duration versus survival in nonemergency colorectal cancer. Scand J Gastroentero/ 2004, 39:252-258.

24. Roncoroni L, Pietra N, Violi V, Sarli L, Choua O, Peracchia A: Delay in the diagnosis and outcome of colorectal cancer: a prospective study. Eur J Surg Oncol 1999, 25:173-178.

25. Mulcahy HE, O'Donoghue DP: Duration of colorectal cancer symptoms and survival: the effect of confounding clinical and pathological variables. Eur J Cancer 1997, 33:1461-1467.

26. Rupassara KS, Ponnusamy N, Withanage N, Milewski PJ: A paradox explained? Patients with delayed diagnosis of symptomatic colorectal cancer have good prognosis. Colorectal Dis 2006, 8:423-429.

27. Lynch BM, Baade P, Fritschi L, Leggett B, Owen N, Pakenham K, Newman B, Aitken JF: Modes of presentation and pathways to diagnosis of colorectal cancer in Queensland. Med J Aust 2007, 186:288-291.

28. Barrett J, Jiwa M, Rose P, Hamilton W: Pathways to the diagnosis of colorectal cancer: an observational study in three UK cities. Fam Pract 2006, 23:15-19.

29. Trickett JP, Donaldson DR, Bearn PE, Scott HJ, Hassall AC: A study on the routes of referral for patients with colorectal cancer and its effect on the time to surgery and pathological stage. Colorectal Dis 2004, 6:428-431.

30. Gunnarsson H, Holm T, Ekholm A, Olsson L: Emergency presentation of colorectal cancer is most frequent during summer. Colorectal Dis 2010, 13:663-638.

31. Nascimbeni R, Ngassa H, Di Fabio F, Valloncini E, Di Betta E, Salerni B: Emergency surgery for complicated colorectal cancer. A two-decade trend analysis. Digest Surg 2008, 25:133-139.

32. Tekkis PP, Poloniecki JD, Thompson MR, Stamakis JD: Operative mortality in colorectal cancer: prospective national study. BMJ 2003, 327:1196-1201.

33. Cleary J, Peters TJ, Sharp D, Hamilton W: Clinical features of colorectal cancer before emergency presentation: a population-based case-control study. Fam Pract 2007, 1:3-6.

34. Olsson L, Bergkvist L, Ekbom A: Symptom duration versus survival in non-emergency colorectal cancer. Scand J Gastroenterol 2004, 39:252-258.

35. Tekkis PP, Kinsman R, Thompson MR, Stamakis JD: The Association of Coloproctology of Great Britain and Ireland study of large bowel obstruction caused by colorectal cancer. Ann Surg 2004, 240:76-81.

36. Jestin P, Pahlman L, Glimelius B, Gunnarsson U: Cancer staging and survival in colon cancer is dependent on the quality of the pathologists' specimen examination. Eur J Cancer 2005, 41:2071-2078.

37. McArdle CS, Hole DJ: Emergency presentation of colorectal cancer is associated with poor 5-year survival. Br J Surg 2004, 91:605-609.

38. Roncoroni L, Pietra N, Violi L, Sarli L, Choua O, Peracchia A: Delay in diagnosis and outcome of colorectal cancer: a prospective study. Eur J Surg Oncol 1999, 25:173-178.

39. Thorne K, Hutchings HA, Elwyn G, Thorne K, Hutchings HA, Elwyn G: The effects of the Two-Week Rule on NHS colorectal cancer diagnostic services: a systematic literature review. BMC Health Serv Res 2006, 6:43.

40. Khattak I, Eardley NJ, Rooney PS: Colorectal cancer - a prospective evaluation of symptom duration and GP referral patterns in an inner city teaching hospital. Colorectal Dis 2006, 8:518-521.

41. Chaplin A, Curless R, Thomson R, Barton R: Prevalence of lower gastrointestinal symptoms and associated consultation behaviour in a 
British elderly population determined by face-to-face interview. $\mathrm{Br} J \mathrm{Gen}$ Pract 2000, 50:798-802.

42. Basaranoglu M, Celebi S, Huseyin A, Rahman S, Deveci ES, Acik Y: Prevalence and consultation behavior of self-reported rectal bleeding by face-to-face interview in an Asian Community. Digestion 2008, 77:10-15.

43. Byles JE, Redman S, Hennrikus D, Sanson-Fisher RW, Dickinson J: Delay in consulting a medical practitioner about rectal bleeding. J Epidemiol Commun H 1992, 46:241-244

44. Crossland A, Jones R: Rectal bleeding: prevalence and consultation behaviour. BMJ 1995, 19:486-488.

45. Kocher HM, Saunders MP: Complacency or ignorance about rectal bleeding. Colorectal Dis 1999, 1:332-333.

46. Macleod U, Mitchell E, Burgess C, Macdonald S, Ramirez AJ: Risk factors for delayed presentation and referral of symptomatic cancer: evidence for common cancers. Br J Cancer 2009, 101:92-101.

47. Mitchell ED, Macdonald S, Campbell NC, Weller D, Macleod U: Influences on pre-hospital delay in the diagnosis of colorectal cancer: a systematic review. Br J Cancer 2008, 98:60-70.

48. O'Mahony M, Hegarty J: Help seeking for cancer symptoms: A review of the literature. Oncol Nurs Forum 2009, 36:178-184.

49. Ramos M, Arranz M, Taltavull M, March S, Cabeze E, Esteva M: Factors triggering medical consultation for symptoms of colorectal cancer and perceptions surrounding diagnosis. Eur J Canc Care 2009, 19:192-199.

50. Smith LK, Pope C, Botha JL: Patients' help-seeking experiences and delay in cancer presentation: a qualititative synthesis. Lancet 2005, 366:825-831.

51. Lee V, Robinson A, Kennedy A, Tomenson B, Rogers A, Thompson D: Functional bowel disorders in primary care: Factors associated with health-related quality of life and doctor consultation. J Psychosom Res 2008, 64:129-139.

52. Halder SLS, Macfarlane GJ, Thompson D, O'Brien SJ, Musleh M, McBeth J: Predictors of persistent gastrointestinal symptoms among presenters to primary care. Eur J Gastroenterol Hepatol 2009, 22:296-305.

53. McEvoy M, Smith W, D'Este C, Duke J, Peel R, Schofield P, Scott R, Byles J, Henry D, Ewald B, Hancock S, Smith D, Attia J: Cohort profile: The Hunter Communtiy Study. Int J Epidemiol 2010, 39:1452-1463.

54. Courtney RJ, Paul CL, Sanson-Fisher RW, Macrae F, Attia J, McEvoy M: Current state of medical-advice-seeking behaviour for symptoms of colorectal cancer: determinants of failure and delay in medical consultation. Colorectal Dis 2012, 14:222-229.

55. Ware JE, Sherbourne CD: The MOS 36-item short-form health survey (SF-36). Conceptual framework and item selection. Med Care 1992, 30:473-483.

56. Kessler RC, Barker PR, Colpe L, Epstein JF, Gfroerer JC, Hiripi E, Normand SL, Manderscheid RW, Walters EE, Zaslavsky AM: Screening for serious mental illness in the general population. Arch Gen Psychiatry 2003, 60:184-189.

57. Ware J: SF-36 Health Survey Update. http://www.sf-36.org/tools/sf36.shtml.

58. Eslick GD, Kalantar JS, Talley NJ: Rectal bleeding: epidemiology, associated risk factors, and health care seeking behaviour: a population-based study. Colorectal Dis 2009, 11:921-926.

59. Talley NJ, Jones M: Self-reported rectal bleeding in a United States Community: Prevalence, risk factors, and health care seeking. Am J Gastroenterol 1998, 93:2179-2183.

60. Farquharson SM, Heald RJ: Anal bleeding survey. Lancet 1994, 344:751-752.

61. Cuffy M, Abir F, Audisio RA, Longo WE: Colorectal cancer presenting as surgical emergencies. Surg Oncol 2004, 13:149-157.

62. Hargarten SW, Richardson MJ, Anderson AJ, Roberts MJ: Cancer presentation in the emergency department: a failure of primary care. Am J Emerg Med 1992, 10:290-293.

63. Khattak I, Eardley NJ, Rooney PS: Colorectal cancer - a prospective evaluation of symptom duration and GP referral patterns in an inner city teaching hospital. Colorectal Dis 2006, 8:518-521.

64. Juel K, Christensen K: Are men seeking medical advice too late? Contacts to general practitioners and hospital admissions in Denmark 2005. J Publ Health 2008, 30:111-113.

65. Smith JA, Braunack-Mayer A, Wittert G: What do we know about men's help seeking and health servcie use? Med J Aust 2006, 184:81-83.

66. Eslick GD, Kalantar JS, Talley NJ: Rectal bleeding: epidemiology, associated risk factors, and health care seeking behaviour: a population-based study. Colorectal Dis 2008, 11:921-926.

67. Mitchell E, Macdonal S, Campbell NC, Weller D, Macleod U: Influences on pre-hospital delay in the diagnosis of colorectal cancer: a systematic review. Br J Cancer 2008, 98:60-70.
68. Simon AE, Waller J, Robb K, Wardle J: Patient delay in presentation of possible cancer symptoms: The contribution of knowledge and attitudes in a population sample from the United Kingdom. Canc Epidemiol Biomarkers Prev 2010, 19:2272-2277.

69. Cykert S, Kissling G, Layson R, Hansen C: Health insurance does not guarantee access to primary care: a national study of physicians' acceptance of publicly insured patients. J Gen Intern Med 1995, 10:345-348.

70. Roetzheim RG, Pal N, Gonzalez EC, Ferrante JM, Van Durme DJ, Krischer JP: Effects of health insurance and race on early detection of cancer. Am J Public Health 2000, 90:1746-1754.

71. McDavid K, Tucker TC, Sloggeett A, Coleman MP: Cancer survival in Kentucky and health insurance coverage. Arch Intern Med 2003, 163:2135-2144.

72. Kelz RR, Gimotty PA, Polsky D, Norman S, Fraker D, DeMichele A: Morbidity and mortality of colorectal carcinoma surgery differs by insurance status. Cancer 2004, 101:2187-2194.

73. Roetzheim RG, Pal N, Tennant C, Voti L, Ayanian JZ, Schwabe A, Krischer JP: Effects of health insurance and race on early detection of cancer. J Nat Canc Inst 1999, 91:1409-1415.

74. Macleod U, Mitchell ED, Burgess C, Macdonald S, Ramirez AJ: Risk factors for delayed presentation and referral of symptomatic cancer: evidence for common cancers. Br J Cancer 2009, 101:92-101.

75. Bowel Cancer Australia: Don't sit on your symptoms awareness campaign http://bowelcanceraustralia.org/bca/.

76. Beating Bowel Cancer: Don't sit on your symptoms campaign. http///umw. beatingbowelcancer.org/sites/default/files/page_files/SymptomsV3.0March2011_0.pdf.

77. Britt H, Miller GC, Charles J, Henderson J, Bayram C, Pan Y, Valenti L, Harrison C, Fahridin S, O'Halloran J: General practice activity in Australia; 2008-09. http://www.aihw.gov.au/publication-detail/?id=6442468257.

78. Eastman P: Collaborative study aims for earlier detection of ovarian cancer in primary care. Oncol Times UK 2010, 7:17.

79. Australian Cancer Network Colorectal Cancer Guidelines Revision Committee: Clinical practice guidelines for the prevention, early detection and management of colorectal cancer. http//uww.nhmrc.gov.au/guidelines/publications/cp106.

80. National Institute for Health and Clinical Excellence: Referral guidelines for suspected cancer. http://www.nice.org.uk/CG027.

doi:10.1186/1471-230X-12-100

Cite this article as: Courtney et al: Factors associated with consultation behaviour for primary symptoms potentially indicating colorectal cancer: A cross-sectional study on response to symptoms. BMC Gastroenterology 2012 12:100.

\section{Submit your next manuscript to BioMed Central and take full advantage of:}

- Convenient online submission

- Thorough peer review

- No space constraints or color figure charges

- Immediate publication on acceptance

- Inclusion in PubMed, CAS, Scopus and Google Scholar

- Research which is freely available for redistribution 